\title{
A review from mesenchymal stem-cells and their small extracellular vesicles in tissue engineering
}

\author{
ODIN RAMIREZ-FERNANDEZ ${ }^{1,2}$; EsMERALDA ZUÑIGA-AGUILAR 3 ** \\ ${ }^{1}$ Universidad Tecnologica de Mexico-UNITEC Mexico-Campus en Linea, Col. Anáhuac, Ciudad de México, 11320, Mexico \\ 2 Department of Biomedical Engineer, Universidad Politecnica de Chiapas, Col. Las Brisas, Suchiapa, 29150, Mexico \\ 3 Department of Electrical and Computational Engineer, Universidad Autónoma de Ciudad Juárez, Instituto de Ingeniería y Tecnología, Ciudad Juárez, \\ 32310, Mexico
}

Key words: Tissue engineering, Mesenchymal stem cells, Small extracellular vesicles, Acute graft-versus-host disease, Cell culture, Cell differentiation

\begin{abstract}
This review aims to offer a vision of the clinical reality of cell therapy today in intensive medicine. For this, it has been carried out a description of the properties, functions, and Mesenchymal Stem Cells (MSCS) sources to subsequently address the evidence in preclinical models and studies clinical trials with whole cells and models attributed to small extracellular vesicles (sEVs), nanoparticles made up of microvesicles secreted by cells with an effect on the extracellular matrix, and their impact as an alternative towards cell-free regenerative medicine. MSCs are cells that enhance the regenerative capacity which can be differentiated typically in different lineages committed as bone, cartilage, and adipose tissue. On the other hand, small extracellular vesicles are structures that participate notoriously and crucially in intercellular communication, which has led to a change in the concept of the functions and the role that these vesicles play in living organisms, in the restoration of damaged tissues and the inflammatory response and immunological. We present the mechanisms that are involved in the applications of MSCS as whole cells and their sEVs in cell therapy and cell-free therapy as an alternative in regenerative medicine. Considering the structural loss that occurs after surgical procedures for cystic and tumoral pathology in periodontitis, as well as the maxillary atrophy that determines the rehabilitation with dental implants, it is imperative to find satisfactory solutions. The opportunity provided by the findings in stem cells is a recent introduction in the field of oral surgery, based on the regenerative potential that these cells possess to restore defects at different levels of the oral cavity. This review aims to discover the real applications that stem cells may have in our treatments shortly.
\end{abstract}

\section{Introduction}

Cell therapy and regenerative medicine have generated a great research boom thanks to new knowledge about stem cells and their potential outlining them as one of the disciplines, more promising companies in the biomedical field, to achieve each of the advances in need of an integration multidisciplinary different specialties such as cell biology, hematology, immunology, biology molecular, tissue engineering, transplantology, clinical research and regenerative medicine (Colter et al., 2000).

The stem cells (SC) are the natural units from which all cell types of the body (Alvarez et al., 2012) They can be indefinitely divided into suitable conditions and differentiate one or different

${ }^{\star}$ Address correspondence to: Esmeralda Zuñiga-Aguilar, esmeralda.zuniga@uacj.mx

Received: 07 April 2021; Accepted: 02 July 2021 types of cells not only morphologically if not also by the functional way they can also be classified according to their potential differentiation and stage of development:

1. Totipotential SC, produce the tissues of the body and the embryonic valve; 2 . Pluripotential SC, capable of differentiating to the 3 lines germ (endoderm, mesoderm, and ectoderm), but not originating membrane cells additional embryonic. Multi-potential SC capable of producing a limited number of differentiated cell lines according to your location. Unipotent SCs originate from specific cell types (Angelos and Kaufman, 2015). The problem with those cells is the possibility of teratoma formation or tumorigenesis processes, so their uses are limited in addition to many ethical and legal aspects. However, there is an alternative using non-embryonic or adult stem cells that can be obtained from organs and body fluids (Dominici et al., 2006; Pittenger et al., 1999).

Mesenchymal Stem Cells (MSCS) are found in different tissues and organs, and they can proliferate and differentiate into many kinds of cell types. MSCS has been extensively 
studied in all fields of medicine due to two fundamental characteristics that possess the high proliferation rate and clonal regeneration by split symmetrical (self-renewal) and its high degree of potential to differentiate into different cell types through asymmetric divisions (differentiation). Various studies have generated a great amount of information about your biology and possible applications (Burrello et al., 2016). The hopes of improving quality of life for human and animal patients advances as technology advances and research, therefore different innovative proposals have emerged within these therapies and treatments with the use of stem cells directing their focus mostly on diseases chronic and degenerative based on immunomodulation and tissue repair (Friedenstein et al., 1976).

MSCS were isolated by Friedestein in 1968 from the bone marrow (MO) of mice and guinea pigs. They were initially described as adherent unit-generating cells that growth around themselves to form fibroblast colony-forming, The stromal cell precursors have been identified in bone marrow from a variety of species, including humans, by their ability to generate from single-cell suspensions of bone marrow colonies of fibroblast-like cells originating from single clonogenic progenitors termed fibroblast colonyforming cells (CFU-F), constitutive of the medullary stroma, and whose function was to maintain the hematopoietic microenvironment. Later studies demonstrated the ability proliferation of CFU-Fs, their ability to self-renew, and their potential to originate adipocytes, chondrocytes, and osteoblasts. This ability to originate cells belonging to mesenchymal tissues suggested the existence of a stem cell present in the OM, which was called years later as MSC (Horwitz et al., 2005). The assay consisted of placing the bone marrow in culture dishes and the nonadherent cells were removed after 4 hours, thus discarding most of the hematopoietic cells. They reported that the adherent cells were heterogeneous, but the most strongly adherent cells were fusiform in shape and formed colony units, which remained inactive for 4 days and then began to multiply quickly. After passing several times in culture, the adherent cells became more fibroblastic in appearance (Bab et al., 1986).

These cells are easily isolated and expanded in vitro. They are multipotential, differentiating themselves towards adipocytes, osteoblasts, chondrocytes, tenocytes, myocytes, hematopoietic stroma, and fibroblasts. They have the plasticity to differentiate themselves ex vivo to non-mesodermal tissues, such as neurons, astrocytes, oligodendrocytes, pneumocytes, and hepatocytes. The International Society for Cell Therapy (ISCT) has suggested minimum criteria for define MSC: a) adherence to low plastic standard growing conditions; b) expression of surface markers like CD105, CD90, CD73 and absence of markers, especially hematopoietic, including CD45, CD34, CD14, and CD11b; c) in-vitro differentiation capacity towards the other lineages of mesodermal origin (adipocytes, chondrocytes, osteoblasts) or if it is necessary to prove their plasticity (neuronal or endothelial differentiation) (Haynesworth et al., 1992, Castro-Malaspina et al., 1980).

Different stem cells sources have been proposed for their potential therapeutic application.

- Embryonic stem cells: Cells obtained from the internal cell mass of unused embryos. They are pluripotent cells that have a unique combination of histocompatibility genes, inherited from sperm and the ovum, so they would be rejected in a histoincompatible allogeneic transplant (Golchin et al., 2020).

- VSEL cells (Very Small Embryonic-Like stem cells): they are a population of embryonic cells with pluripotent characteristics that derive from germ cells and can be isolated from adult tissue. This cells, express embryonic markers, are deposited in the developing organs during embryogenesis and play a role as a support population for the stem cells committed to a certain tissue (Lukomska et al., 2019).

Nowadays, some research groups turn to use nonembryonic stem cells, known as Induced Pluripotent Stem Cells (iPSC), those cells are derived from adult cells by transfer (transfection) of various exogenous genes associated with SC cells. Generally, for efficient transfer, retroviruses have been used that act as vehicles or vectors of exogenous genes. The exogenous genes transferred are mainly those corresponding to transcription factors (gene transcription) associated with embryonic cells. After 3-4 weeks, a small percentage of the transferred cells begin to differentiate, becoming morphologically and biochemically like SC cells. IPS cells or reprogrammed adult cells are isolated by selection for an antibiotic resistance gene and by confirmation of its identity (Nakahara et al., 1991).

Shinya Yamanaka's team at the University of Kyoto (Japan) in 2006, was the first to generate iPS cells. To do this, they used mouse fibroblasts as target cells, as exogenous genes, previously identified as expressed in ES cells, and retroviruses as vehicles or vectors. Four genes encoding transcription factors were essential to producing iPS cells: the so-called Oct-3/4, Sox2, c-Myc, and Klf4 (Kumar et al., 2019). From the cells treated with retrovirus encoding said genes, those that expressed them with antibiotics and by the presence of the Fbx15 gene (Fbx15 + cells) were selected. However, these iPS cells had different DNA methylation patterns from ES cells and did not produce viable chimeric mice (Pittenger et al., 1999).

Regenerative medicine based on cell therapy with the use of MSCS has become a recurring subject of research and clinical trials in humans on an international scale in recent years. This therapy presents therapeutic options that range from the implantation of the whole tissue as in bone marrow transplantation or the injection of isolated or mixed autologous cells (Keshtkar et al., 2018). However, the MSCS in regenerative medicine is complemented with the effects of their paracrine factors emitted by them with anti-inflammatory properties, immunological reprogramming, and activation of regenerative pathways by various mechanisms due to small molecules, such as growth factors, cytokines, and chemokines, which are secreted by very low concentrations in the cellular environment and that contribute to the therapeutic effect (Horwitz et al., 1999).

It is currently recognized that in addition to soluble elements, these cells also release extracellular vesicles (EVs) that comprise a group of highly heterogeneous structures both in size and shape, as well as in their content and the functions they perform (Han et al., 2019). The paracrine hypothesis was inspired to replace the MSCs with the EVs 
isolated from the extracellular medium and apply them (Chen et al., 2016).

Generally, three main types of EVs are distinguished according to their diameter and functions: apoptotic bodies (1-5 $\mu \mathrm{m})$, microvesicles (MVs) $(100 \mathrm{~nm}-1 \mu \mathrm{m})$ and small extracellular vesicles (sEVs) $(30-100 \mathrm{~nm})$, with biological activity like the cells; They are distinguished from the previous structures by their morphology and size. sEVs are nanoparticles made up of microvesicles secreted by cells with an effect on the extracellular matrix. In multiple publications it is stated that they constitute key elements in intercellular communication and the modulation of cellular immunity with therapeutic effects; this has been a revolutionary advance for regenerative medicine by achieving encouraging results without the direct application of the cells that generate them (Sarker et al., 2014).

\section{MSC characterization and multipotentiality}

MSCS are currently the most studied stem cells in medicine, due to its ease of obtaining by minimally invasive procedures and for its therapeutic potential and all components that make them optimal for regenerative and tissue medicine (Duscher et al., 2016). MSCS has a low rate of growth in vivo but have high regeneration and differentiating capacity into various cell types, thus managing to replace cells that are lost due to disease or lesions in vitro and are characterized by their adherence and morphology of fibroblasts (Heil et al., 2004). As well, they generate acceleration in the processes of scarring due to the positive effects that they bring in each of the phases of the said process (inflammatory, proliferative, and remodeling) creating an increase in epithelial migration, angiogenesis, and cure rate (Hooper et al., 2012).

The most used sources for isolation of MSCs are bone marrow tissue, adipose, and periosteum, although obtained from peripheral blood, muscle, periodontal ligament, articular cartilage, etc. Currently, different studies show that we could use extraembryonic like membrane amniotic, extravascular cord matrix, umbilical blood, and umbilical cord blood since from these sources it is possible to collect at delivery with a noninvasive technique (Ibrahim et al., 2014).

Morphologically, MSCS is characterized by having a spindle-shaped, spindle-shaped morphology with the presence of an elongated, central nucleus that contains two to three nucleoli. Although some authors have reported that cell layers contain cells that are homogeneous in their morphology, there is more evidence that these layers are heterogeneous and contain cells that are morphologically and functionally distinct. Since the first studies by Ashton et al. (1980), it was observed that the mesenchymal cell progenitor colonies contained various types of cells. Those authors described colonies containing spindle fibroblast cells, which formed compact colonies and open colonies; another type of cells, which they called the epithelial type, were smaller cells, with nuclei more intensely stained and morphologically like epithelial cells. The research published by Mets and Verdonk emphasized the presence of two cell types, one called Type I, in which the cells were small and spindle-shaped, and Type II, which were larger, flattened and that proliferated slowly as shown in Fig. 1 (Lai et al., 2015).

Studies by Prockop et al. showed in flow cytometric studies, three subpopulations, one of the small, spindle, and agranular cells, which they named RS-1; another one with small and granular cells, called RS-2; and the last one made up of larger and granular cells which they called mature mesenchymal cells or mMSC. Those authors postulated that RS-1 cells correspond to MSC progeny, with a high proliferation index, which gives rise to RS-2 cells and the latter to mMSCs. However, so far this is only a hypothesis, and it is necessary to carry out functional studies to corroborate it. Most of the cells were spiky with fibroblast morphology, and a smaller proportion of cells in the culture had a larger size and rhomboid morphology. (Ashton et al., 1980).

The ISCT defines that MSCS could express different surface markers, expressing CD105 (SH2), CD73 (SH3/4), CD44 (H-CAM), CD90 (Thy-1), CD71, and Stro-1, as well as adhesion molecules CD106 (vascular cell adhesion molecule [VCAM]-1), CD166 (Leukocyte cell adhesion molecule activator [ALCAM]) (Flores-Figueroa et al., 2005; Prockop et al., 2001; Colter et al., 2000; Campagnoli et al., 2001; In'tAnker et al., 2003; Nakahara et al., 1991; Pittenger et al., 1999; Trounson and McDonald, 2015; Bieback and Brinkmann, 2010). And MSCS should not express the group of hematopoietic stem markers CD45, CD34, CD14 or CD11 and HLA-DR (positives for Hematopoietic Stem Cells) (Flores-Figueroa et al., 2005). MSCS also do not express costimulatory molecules CD80, CD86, or CD40 or adhesion molecules CD31 (adhesion of platelet/endothelial cells)

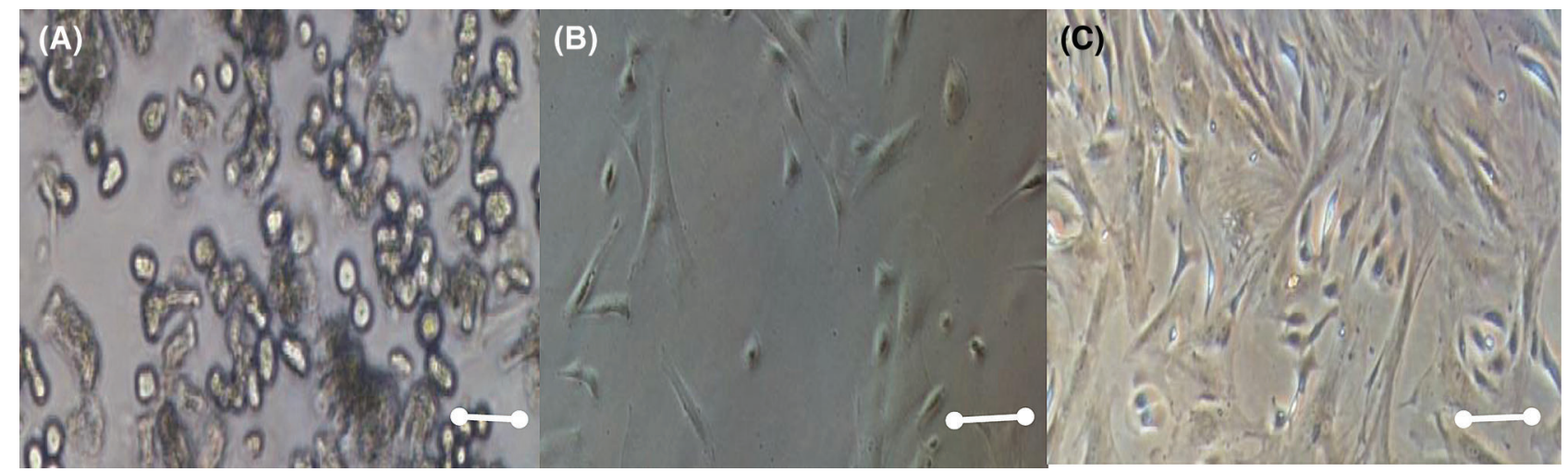

FIGURE 1. Mesenchymal stem cell morphology at different days, A) 2 days culture, B) 8 days culture, C) 15 days culture. Scale bar $600 \mu \mathrm{m}(400 \times)$. 
molecule [PECAM]-1), CD18 (antigen associated with leukocyte function) CD56 (cell adhesion molecule) neuronal-1.

There are also variable expressions of many of the markers due to variation in the tissue source, methods of isolation and culture, as well as species differences (Mets and Verdonk, 1981; Zuk et al., 2002). For example, human adipose tissue is a source of MSCS that, like cells obtained from bone, can differentiate into several mesenchymal lineages in vitro. However, there are some differences in the expression of markers: CD49d is expressed in cells from adipose tissue, but not in those from the bone. CD106 in bone marrow MSCS has been functionally associated with hematopoiesis, so the lack of expression of CD106 in adipose tissue cells is consistent with the location of these cells in a non-hematopoietic tissue (Trounson and McDonald, 2015). Some groups have created new MSCs specific antibodies that do not recognize other cell types. One of them is STRO-1.

In 1991 was obtained a murine monoclonal antibody by fusion between a murine myeloma cell line and spleen cells of $\mathrm{BALB} / \mathrm{c}$ mice immunized with a population of CD34+ cells from bone marrow but this antibody could recognize erythroid cells and is not expressed in all MSCs.

The group generated several mice immunized hybridoma cell lines with human mesenchymal cells expanded in vitro (Yukawa and Baba, 2017). They obtained three hybridoma cell lines called SH2, SH3, and SH4. These lines secreted antibodies that recognized the antigens on the MSCs surface and did not react with hematopoietic cells or with differentiated cells in bone or cartilage. The SH2 antibody recognizes $\mathrm{CD} 105$ and reacted with bone marrow mesenchymal cells, but not with expanded periosteum cells. SH3 and SH4 recognize the antigen CD73. These three antibodies contribute to the MSCs characterization (Kern et al., 2006).

MSCs are positive for extracellular matrix receptors and various growth factors, such as interleukin 1, 3, 4, 6, and 7 receptors, platelet-derived growth factor receptor (PDGF-R), factor receptor neuronal growth (NGF-R), transforming growth factor-beta 1 and 2 receptors (TGF $\beta R 1$ and TGF $\beta R 2$ ), tumor necrosis factor 1 and 2 receptors (TNFR1 and TNFR2), interferon-gamma receptor (IFN $\gamma$ ), and transferrin, as well as for adhesion molecules, ICAM-1, ICAM-2, VCAM-1, L-selectin, LFA-3, ALCAM, CD105 and CD72, and a variety of integrins ( $\alpha 1, \alpha 2, \alpha 3, \alpha 5, \alpha 6, \alpha v, \beta 1$, $\beta 3$, and $\beta 4$ ). On the other hand, these cells are negative to the following cytochemical reactions: alkaline phosphatase and acid phosphatase. (Horwitz et al., 1999; Piersma et al., 1983; Trounson and McDonald, 2015; Ashton et al., 1980).

The binding transcription factor 4 (Oct4) is present in ESCs and MSCs. The expression of Oct4 and Nanog has been determined in tumor cells, that is the reason because they confirm the high proliferative capacity and viability for prolonged periods in cells. In mammalian cells, the multipotentiality goes under the control of the gene's transcription factors Oct4, Nanog, Sox2, and Fox3; the expression of these genes in MSCs is controversial because they are markers of ESCs, their expression is modified when the cell is committed to a specific lineage initiating the expression of other genes (Jeter et al., 2009; Kong et al., 2010).
The MSCS multipotential capacity began to be demonstrated in vivo in 1976. In these works, we showed that MSCs cultured in vitro and transplanted in mice, produce fibroblasts and osteoblasts. Another work done by Gowen et al. (2020) consisted of culturing rabbit bone marrow cells and transplanting them in vivo. This work demonstrates MSCs can produce connective tissue and chondrocytes. Those cells were negative for Alkaline Phosphatase (AP) and von Kossa staining. These authors demonstrated the MSCS's ability to originate osteoblastic, cartilaginous, and fibroblastic cells. The next work consists of culturing and transplanting human mesenchymal stem cells in nude mice to obtain bone formation. Then, a single MSC colony demonstrated the in vitro osteogenic potential capacity to differentiate into fat cells, osteoblasts, and chondrocytes. From these experiments, made from isolated MSCs colonies, the researchers have shown that the differentiation of the cells depends on their environment and that not all of them have the same differentiation potential that is something remarkable (Ryan et al., 2005; Mauney et al., 2005; Nakahara et al., 1991; Colter et al., 2000; Horwitz et al., 1999).

\section{MSC sources}

MSCs can be obtained from bone marrow, bone, trabecular, adipose tissue, synovial membrane, amniotic fluid, placenta, umbilical cord blood, dental pulp, skeletal and cardiac muscle, liver, spleen, pancreas, periosteum, dermis, lung, menstrual blood, peripheral blood, and periodontal ligament (Fig. 2) (Mets and Verdonk, 1981; Flores-Figueroa et al., 2005; Prockop et al., 2001; Lakshmipathy and Verfaille, 2005; Campagnoli et al., 2001). The main sources are bone marrow, adipose tissue, and umbilical cord blood (Friedenstein et al., 1976; In'tAnker et al., 2003). Once MSCs are isolated by plastic adhesion and cultured in vitro, they can differentiate into different mesodermal lineages such as osteocytes, chondrocytes, adipocytes, myoblasts, and cardiomyocytes (Lane et al., 2005; Nakahara et al., 1991; Zuk et al., 2002; Gálvez et al., 2011), or they can differentiate into endodermal cells like hepatocytes, pancreatic cells and ectodermal cells like astrocytes and neurons (Trounson and McDonald, 2015; Bieback and Brinkmann, 2010; Zomer et al., 2015).

\section{MSCS from Bone Marrow}

They were first described in 1970 and isolated in the dog in 1977 by Kadiyala et al. (1997) In canines, marrow is easily accessible and minimally invasive in places like sternum, ribs, coxal, tibia, humerus, and femur tuberosity. The isolation of these cells has been made by direct sowing by a concentration gradient, being the very low portion in canines $1 / 2500$ and equine $1 / 4200$ (MSCs/cells of the bone marrow) (Park et al., 2019). The place of collection may influence your isolation, being the best location, iliac crest in dogs, old and warm in young, and other factors how the donor's age can influence the quantity and quality of cells (Villatoro, 2015). A study carried out in canines showed low expression of cell markers hematopoietic and high expression of CM CD90 markers, also featuring 

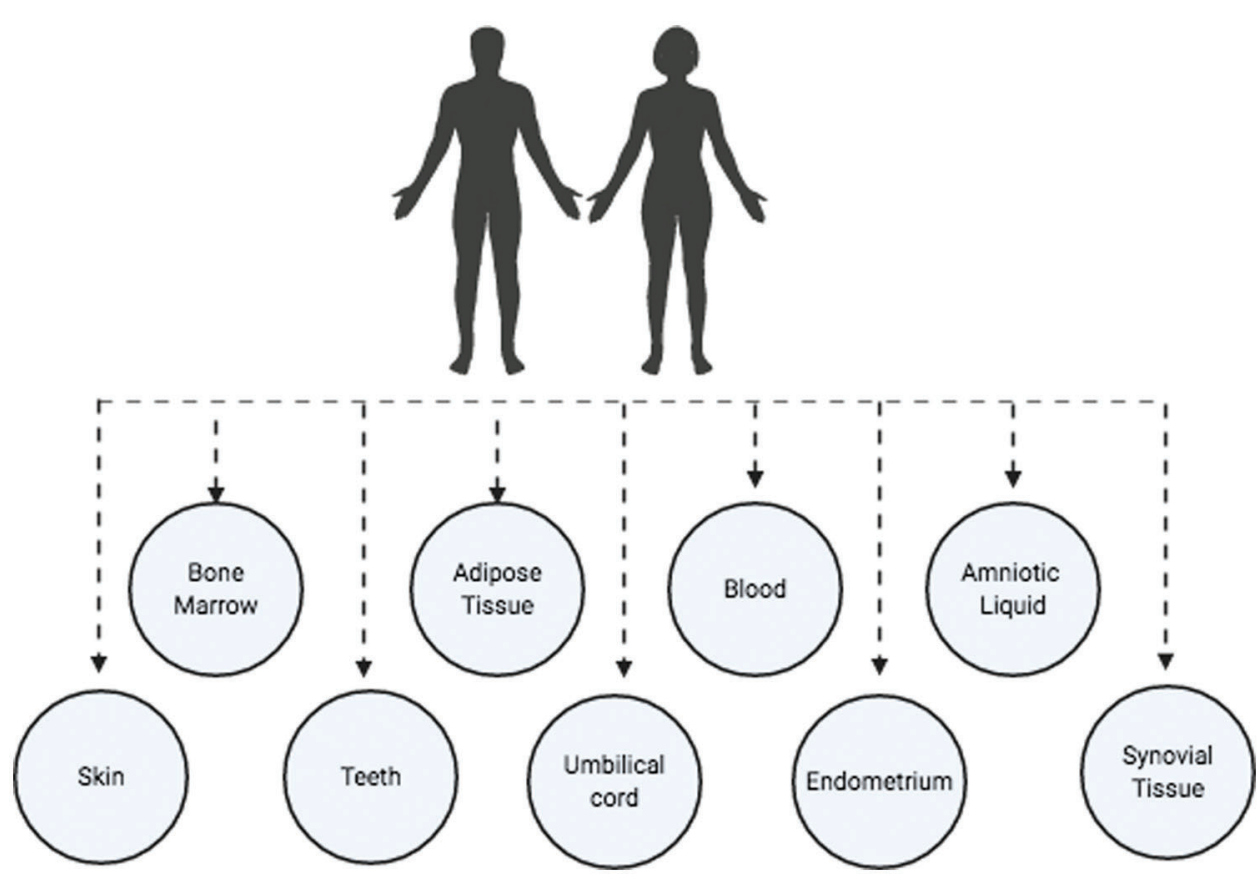

FIGURE 2. Main MSC sources (Figure is made with biorender: https:// biorender.com/).

differentiation into osteoblasts, adipocytes, and chondrocytes (Qiu et al., 2018).

Some researchers have detected cells in the circulation that present characteristics and phenotypes like those of bone marrow MSCs. The presence of this cell has been reported in the peripheral blood of healthy subjects, in the peripheral blood of some animals, and in the peripheral blood of fetuses with a gestational age of 10 to 14 weeks (Herzog et al., 2003; Wakitani et al., 1995; Pereira et al., 1995; Sandhu et al., 1996).

Bone marrow MSCs are easy to isolate, expand in vitro, and manipulate in the cell culture process to obtain the necessary cell numbers that define the cellular dose to administrate in the patient. They can be cryopreserved without phenotypic alterations and preserve their proliferative and differentiating capacity after the process. The undifferentiated cells are subjected to processes in less than seven passes, their karyotype characteristics, and their telomerase activity begins to be affected beyond this pass. This leads to aging of the culture and the appearance of chromosomal alterations while causing the loss of cell multipotentiality (Nauta and Fibbe, 2007; Friedenstein et al., 1968; Kinnaird et al., 2004; Gálvez et al., 2013).

\section{MSCS from adipose tissue}

The subcutaneous adipose tissue has become one of the most used to obtain MSCs in small animals, possible small quantity isolation collected in elective surgery, which were isolated for the first time in canines up to the year 2008 (Ryan et al., 2007) They are found in greater quantity compared to bone marrow MSCs (500 to 100 times more) and allow to be isolated and expanded from very small, besides this, they have a greater capacity for proliferation (Park et al., 2019) Animals have different sources of anatomical fat that are divided into fat, subcutaneous, and internal, depending on this location, adipose tissue presents different metabolic properties, profiles of gene expression, characteristics antigenic, and differentiation potential (Schipanski et al., 2016).

\section{MSCS from amniotic membrane}

The amniotic membrane is a promising alternative source for obtaining MSCS, with high potential for use in regenerative therapy due to already known characteristics of these cells, a study showed stability between chromosomes in addition to propagation in cell culture without loss of quality functional and in vitro differentiation in chondrogenic cell lines, adipogenic, osteogenic and neurogenic showing potential parents, that guarantees its possible use in cell therapies (Sung et al., 2017).

The umbilical cord MSCS express SH-2, SH-3, SH-4, aSMA, CD29, and CD49b, but do not express others such as CD90, CD106, or CD146. Functional studies have shown that umbilical cord blood MSCS can differentiate into chondrocytes, adipocytes, osteoblasts, hepatocytes, myoblasts, and neuronal cells (Ryan et al., 2005; Oswald et al., 2004; Asahara et al., 1997; Reyes et al., 2001; Koch et al., 2013; Tse et al., 2000; Burrello et al., 2016; Ryan et al., 2005; Asahara et al., 1997; Zhao et al., 2002).

Many research groups have published the possibility to obtain MSCS from another source such as amniotic fluid, fetal pancreas, placenta, Wharton gelatin, and adipose tissue, but there is no standardized protocol to obtain and purification of MSCS from these sources and their complete characterization. Therefore, it will be necessary to generate a standard MSC characterization of these alternative sources. A research group reports that there are no morphological differences among the MSCS from bone marrow, umbilical cord blood, and adipose tissue. Their results indicate that MSC umbilical cord blood has an enormous expansion potential, but a lower differentiation (Cohen, 2013; Peired et al., 2016; Lazarus et al., 1995; Reissis et al., 2016; Lazarus et al., 1995; Reissis et al., 2016; Marappagounder et al., 2013; Li et al., 2016; Park et al., 2016).

\section{MSCS from dental pulp}

The dental pulp is a connective tissue richly supplied with blood vessels and nerves, lies within the internal cavity of 
teeth, and it is made up mainly of MSCS that when proceeding from this tissue, its biological function consists of repairing dentin and enamel, which are derived from the ectoderm of the neural crest and therefore constitute a true cellular reserve. Dental pulp can be recovered from teeth that are extracted in procedures routine dental practice and normally are considered a waste product biological (Wang et al., 2004).

\section{MSC plasticity}

Cellular plasticity is defined as the ability of a cell to differentiate into different mature cells from those of its germ tissue origin; it is the cell flexibility to overcome the lineage barrier and adopt expression profiles and functional phenotypes of cells from other tissues, MSCS can differentiate into mesodermal cells, as well as adopt an endodermal or ectodermal destiny (Piersma et al., 1983).

The MSC's ability to differentiate in vivo in spleen, cartilage, bone marrow, and bone tissue cells was demonstrated, the study may consist in cultivating MSCs with a mutation in the gene of collagen type I, which allows its monitoring. The cells were transplanted in an irradiated mouse, and after five months it was observed that the donor cells represented up to $12 \%$ of the cells of bone marrow, spleen, bone, cartilage, and lung (Pereira et al., 1998).

Other experiments found that MSCS, after two months of being transplanted in an immune-deficient mouse, growth into the mesenchymal tissues (marrow and spleen), and in the liver, thymus, and lung. These experiments suggest that these cells replace a proportion of the MSCs of the recipient in the bone marrow and that they participate in normal biological functions, serving as a source of progeny cells of various tissues (Menard et al., 2013).

The undifferentiated MSCS express characteristic neural markers like the microtubule-associated 1B protein (MAP1B) and vimentin. When treating the cultures with neural inducers, which increase the levels of intracellular cAMP, many cells acquired a typical neural cell morphology, associated with an increase of neuron-specific enolase (NSE) and vimentin. These neural cells have been obtained by using only small diameter MSCs cell layers (Zuk et al., 2002; Safford et al., 2002; Oswald et al., 2004; Gimble et al., 2008; Kim and Cho, 2013).
In vivo and in vitro studies demonstrate that the MSCs plasticity is supported through the microarray and microSAGE expression technique, that these cells express transcripts not only of the mesenchymal lineages (adipocytes, chondrocytes, myoblasts, osteoblasts, and stromal fibroblasts) but also express transcripts characteristic of epithelial, neuronal and endothelial lineage. Depending on the origin of the MSC, the expression of surface markers varies, thus MSCs derived from adipose tissue express higher levels of surface antigens: CD34, CD49d, and CD54; Bone marrow MSCs express higher levels of the CD106 surface antigen and MSCs obtained from umbilical cord blood hardly express the CD9017 surface antigen (Gonda et al., 2008; DiGirolamo et al., 1999).

\section{Small extracellular vesicles (sEVs)}

Small extracellular vesicles (sEVs) are microvesicles that originate in the endosomal compartment by fusion of the body multivesicular with the plasma membrane. The terms microvesicles, ectosome, or vesicles released would correspond to particles directly originated from the plasma membrane. Although the bibliography indicates that small extracellular vesicles are particles with a diameter less than $100 \mathrm{~nm}$ and microvesicle particles greater than $100 \mathrm{~nm}$, according to the International Society for Extracellular Vesicles (ISEV), the strict separation by size or origin has not yet been exactly established, nor is there a consensus on the markers that can distinguish the origin of these vesicles as shown in Fig. 3 (Cvjetkovic et al., 2014).

Small extracellular vesicles are secreted by most of the cell types and can be isolated from both supernatants' cells in culture and different biological fluids. Small extracellular vesicles are involved in intercellular relationships, allowing the exchange of proteins and lipids between small extracellular vesicle-producing cells and target cells. These microvesicles contain RNA, micro-RNA, and proteins from their cells of origin, which confer an important signaling mechanism in physiological processes, including tumor progression, angiogenesis, and module immune response modulation (Qiu et al., 2018).

There are different methods for isolating sEVs, although the most widespread is ultracentrifugation. This method is

\section{EXOSOMES}

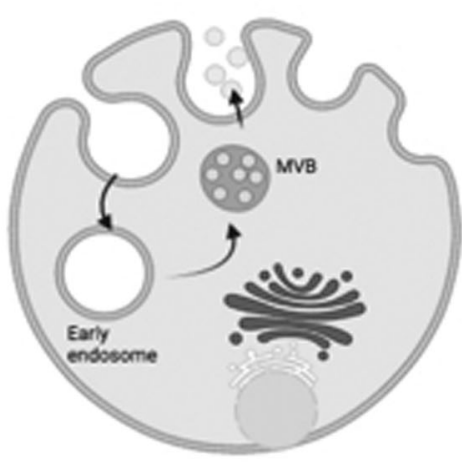

MICROVESICLES

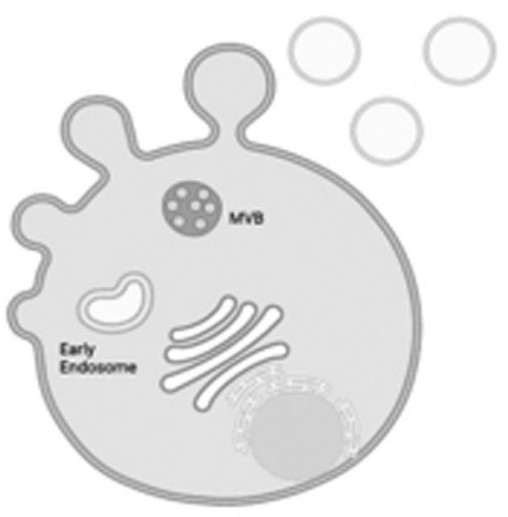

APOPTOTIC BODIES

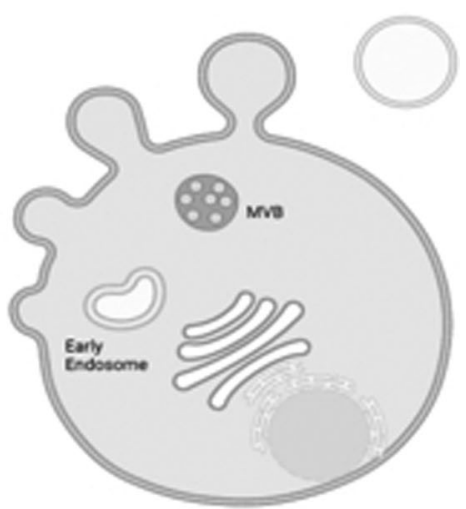

FIGURE 3. Schematics of Exosomes (Small Extracellular Vesicles), microvesicles, and apoptotic bodies schematic (Figure is made with biorender: https://biorender.com/). 
often combined with gradients of sucrose and requires equipment suitable. Other methods include High-Performance Liquid Chromatography, Liquid Chromatography, HPLC), ultrafiltration, polymer precipitation, and immunoseparation based on magnetic particles (Sarker et al., 2014).

The use of sEVs for the treatment of different pathologies has been studied at the preclinical level where safety, efficacy, and tolerability have been demonstrated widely. In recent years, clinical trials using derived exosomes from dendritic cells for the treatment of patients with cancer. Currently, the therapeutic potential of sEVs derived from MSCS for the treatment of pathologies of cardiovascular origin has been shown in animal models. In this sense, sEVs have been used from bone marrow in a murine model of myocardial ischemia-reperfusion resulting in a beneficial effect on reducing tissue damage (Gowen et al., 2020).

Most sEVs possess a group of evolutionarily conserved proteins such as tetraspanins (CD81, CD63, and CD9), heat shock proteins (HSP60, HSP70, and HSP90), ALIX, and the tumor-susceptible gene 101 (TSG101), as well as Specific and unique proteins depending on the tissue type that reflect the cells of their origin. As a result of their high selectivity and their ability to carry messages between different cell types, along with their small diameter and low immunogenicity, they have become understudy as therapeutic agents in cardiovascular, musculoskeletal, bronchopulmonary, dermatological, neurodegenerative, and oncological diseases, among others (Cvjetkovic A, 2014). They also act as possible endogenous vectors for the transport of drugs due to their immunomodulatory action. Another aspect is that alterations in their characteristics are detected in many diseases, such as cancer, which suggests its importance is not only therapeutic but also diagnostic (Gowen et al., 2020).

The abundant content of the cargo identified in the sEVs from MSCS (sEVs-MSC) makes them work mainly through the constant transfer of microRNAs (miRNAs) and proteins, $>150$ miRNAs and $>850$ unique proteins. It results in the alteration of various types of activities in the target cells by different pathways since many miRNAs of these sEVs have been found involved in physiological but also pathological processes, such as the development of organisms, epigenetic regulation, and immunoregulation. They interact with target cells by adhesion to their surface through receptors that act as lipid ligands, internalization via endocytic capture, or by direct fusion of these vesicles with the cell membrane, which results in the release of the content or charge of the exosome within the target cell, thus modulating the physiology of the target cell and influencing the biology of the tissue and the organism (Giebel et al., 2017)

sEVs-MSCS can carry antigenic material and express functional major histocompatibility system (HPS) antigens, resulting in the potential to mediate the immune response through antigen presentation. It could explain their potent immunomodulatory properties and is said to play a prominent role in transporting and presenting functional complexes of peptide-bound HPS antigens, for example, to modulate the activation of specific antitumor T cells (Giebel et al., 2017).

MSCS was found to be bone marrow sex is effective in buffering graft versus host disease (cGVHD) in mice by inhibiting the activation and infiltration of $\mathrm{CD} 4+\mathrm{T}$ lymphocytes. This achieves the reduction of proinflammatory lymphokine secretion and improves the generation of regulatory $\mathrm{T}$ cells with the expression of IL-10 and inhibition of TH17 cells. EVs derived from human multipotent stromal cells suppress autoimmunity. in an animal model of type 1 diabetes (T1D) and experimental autoimmune uveoretinitis (Giebel et al., 2017).

Exo-MSCS from human bone marrow promotes Treg cell proliferation and immunosuppressive capacity through action on IL-10 cytokines and tumor growth factor (TGF$\beta 1$ ) in mononuclear cells isolated from peripheral blood in asthmatic patients (Börger et al., 2017).

\section{Clinical application}

The MSC multipotential capacity and their plasticity make them a perfect option for clinical applications. The literature on MSCS reported in the last fifteen years refers precisely to clinical use, which includes diseases of the skeletal, cardiac, nervous, and hematopoietic systems, among others. Once recovered, the cells are cultured ex vivo adhering to the plastic surface of a culture bottle. Population expansion is fast and is done by the sequential transfer of cells to an increasing number of media cultures, being able to reach 20-30 times the original population in less than two weeks. The above allows having available in a short time a stock that can be used for therapeutic purposes (Blazquez et al., 2014).

MSC expansion does not affect multipotentiality and their tumorigenic potential is very low and its ability to differentiate is restricted. They have low immunogenicity, do not express MHC type II molecules or co-stimulatory of $\mathrm{T}$ lymphocytes (CD80, CD86), and have a minimum constitutive expression of MHC type I, which facilitates its use for allogeneic transplant (Gastpar et al., 2005).

They have immunomodulatory properties, they are capable of suppressing responses associated with inflammatory processes promoted by cells of the immune system acquired ( $\mathrm{T}$ helper 1 (Th1), Th17, T-CD8, and B lymphocytes). On the other hand, they induce a response of cells of the immune system associated with anti-inflammatory processes (cell dendritic [DC] type 2 [suppressor], macrophage type 2, Th2 and T regulators) (Burrello et al., 2016).

The studies were carried out to indicate what kind of stem cells are suitable in regenerative medicine. The main characteristic is that they should be nonspecialized cells and have the capacity to self-renew for long periods in addition to their plasticity in specialized cell deafferentation with specific functions. Even though their lower proliferative potential and lower plasticity compared to embryonic stem cells and induced stem cells, but they are easier to obtain from tissues, do not create ethical problems for their manipulation, they have a high expansion capacity in vitro, in addition to low potential for teratogenesis (Kurtzberg et al., 2014).

MSCS got the ability to produce cytokines and growth factors, could migrate to the damaged tissue and got immunomodulatory actions in situ. The MSC study and development of biological characteristics could contribute to offering novel therapeutic alternatives in regenerative medicine and tissue engineering against diseases (Menard et al., 2013). 
Experimental evidence has shown that MSC-derived tissue could be effective in the treatment of different organic dysfunctions including traumatic neural injury, acute respiratory distress syndrome (ARDS), or renal failure. There is preclinical evidence that MSCS may be effective in sepsis treatment. The studies of allogeneic MSCS have focused on the potential therapeutic value of the conditioned media and microvesicles generated (Ashton et al., 1980; Bab et al., 1986; Castro-Malaspina et al., 1980; Giebel et al., 2017).

MSCS after being cultured and expanded in vitro were transplanted intravenously not only hematopoietic cells but also colony-forming units (CFU-F). After three months of having transplanted in an irradiated mouse, $50 \%$ of the CFU-F obtained from bone marrow came from the donor. It was demonstrated that in irradiated mice, MSCs graft not only in bone marrow, but it also grafts in cartilage, spleen, liver, lung, and brain. In humans, MSC therapeutic schemes consist of expanding in vitro and transplanted into patients, causing minimal adverse effects; these cells are tolerated by patients and can be detected at different posttransplant times (Menard et al., 2013; Kurtzberg et al., 2014; Lazarus et al., 1995).

Another MSC therapy is to promote angiogenesis, there is experimental evidence that shows the generation and incorporation of endothelial cells derived from MSCS, to capillaries information, and promote angiogenesis through the secretion of cytokines such as VEGF-A, FGF-2, IL-6, and MCP-1. In myocardial therapy, MSCS is implanted into the heart-damaged area and then begins to remodel the tissue and improve its function, resulting in clinical improvement of the heart patient (Kern et al., 2006; Bab et al., 1986).

The MSC clinic use, which has proven to have no risk to the patient, is not teratogenesis and inhibits immune rejection when they were transplanted. It is important to enhance the study of these cells to know their biology, their differentiation capacity, and their hematological role in diseases, as well as their cell therapy applications in regenerative medicine. MSCS modulates immune reactions in bone marrow transplants and plays a crucial role in the development and differentiation of the lymphohematopoietic system (Tofiño-Vian et al., 2018).

Those cells secrete growth factors and regulatory cytokines that are not detected by the patient immune system and have an immunomodulatory effect. In 1995, it was the first clinical trial with MSCS, where 15 patients were treated with autologous MSCS from bone marrow, the clinical use of these cells has been widely studied (Zhao et al., 2015; Bajada et al., 2008; Bajada et al., 2008).

A great global problem is the unauthorized "stem cell clinics", they use several "stem" cell populations, including "MSCS" from many different sources for various treatments, many without approved protocols. Significantly, liposuction and bone marrow aspiration are the main "Stem Cells" sources, those samples containing many cell types which do not stem cells. It has been difficult to evaluate the effectiveness of these "therapies" because many diseases and disorders that are being treated are reduced and diminished (Bajada et al., 2008).

Nowadays, the first large phase III trial with bone marrow MSCs was realized by the pharmaceutical company Mesoblast (before Prochymal) for the treatment of steroid-refractory graft-versus-host disease (GVHD) (NCT00366145). The trial was completed in 2009 and the results showed a significant improvement in overall response only in children, which allowed the approval of the first therapy with MSCs for the treatment of pediatric GVHD in Canada and Japan. Subsequently, Mesoblast launched a second trial (NCT02336230) completed in 2018, where evaluated the use of allogeneic MSCs in children with GVHD steroid-refractory, the general response was satisfactory (Paik et al., 2020).

Currently, this therapy is on the registration phase at the Food and Drug Administration (FDA) in the USA. Also, Mesoblast have phase III treatments for the Crohn's disease (NCT00482092), chronic heart failure (NCT02032004), chronic low back pain (NCT02412735), and recently, severe acute respiratory syndrome caused by infection with coronavirus-19 where the results show an improvement in respiratory tract of patients who received MSCs against placebo (Qian et al., 2020).

On the other hand, Autologous MSCs from MO previously conditioned in vitro to induce cardiac regeneration have also been tested in a phase III trial by Celyad (Belgium) for the treatment of chronic heart failure (NCT01768702). Similarly, TiGenix sponsored two studies with autologous MSCs (NCT00475410) and allogeneic derived cells from adipose tissue (NCT01541579) for the treatment of complex perianal fistulas in patients without inflammatory bowel disease (Hur et al., 2020).

The European Commission approved the first pharmaceutical agent of MSCs (Alofisel) to treat Crohn's disease-related enterocutaneous fistular disease. Currently, in addition to these clinical studies, TiGenix with 3 active trials in phase III applied to Crohn's disease, severe sepsis, and acute myocardial infarction (Gowen et al., 2020).

On the other hand, the sEVs from MSCS (sEVs-MSCS) and their clinical applications have shown that the results published in preclinical models indicate that Exo-MSCS have enormous therapeutic potential in the treatment of immune-based diseases and pathologies associated with tissue damage (Davis, 2016). Preclinical trials in acute myocardium infarction models have shown that treatment favors the functional recovery of heart tissue. On the other hand, concerning the immunomodulatory role of these sEVs, we have shown that they have a regulatory effect like that described for the cells themselves, with an inhibitory effect on the activation, secretion, and proliferation of $\mathrm{T}$ lymphocytes.

sEVs-MSCS mediate tissue repair processes, they are capable of synthesizing components of the extracellular matrix such as fibronectin, versican, and collagen-1, and soluble factors such as G-CSF, GM-CSF, VEGF, FGF7, IL-6, IL-7, IL-11, TGF- $\beta 1$, SDF-1, among others. sEVsMSC mediated effects occur without the inclusion or grafting of these in a tissue. Studies with detection of fluorescence show that the half-life of the cells after being infused is reduced, with a population less than $1 \%$ one week post-infusion. In this context, sEVs-MSCS would act directly by contacting cells of the immune system or others or, indirectly, by releasing paracrine factors, exercising a coordination action in processes such as tissue repair, neovascularization, apoptosis, phagocytosis, and immunomodulation (Menard et al., 2013). 
The potential advantages of human sEVs-MSC use, it is pointed out that it would avoid the transfer of cells in situations in which adverse effects could occur, such as the existence of mutated or damaged DNA, or a potential pulmonary embolism due to cell implantation. In addition, it can be used in systemic applications, sEVs nanoparticles easily circulate through the body and pass the blood-brain barrier with ease, while MSCS are too large to circulate through the capillaries, so they are largely retained in the pulmonary capillary network. On the other hand, the dose of infused MSCS decreases rapidly after their administration, so it would be possible that the administration of sEVs could achieve a "dose" that circulates through the organism to a greater extent compared to its cellular counterpart (Urbanelli et al., 2015).

However, it is considered that the main disadvantage of using sEVs-MSCS is that the dose would be fixed and unable to reproduce in vivo unlike in cells. In turn, the usefulness and efficacy of sEVs depend on certain critical parameters that include the development of robust and highly reproducible production processes for their production and standardized storage, as well as clinical studies that allow evaluating their therapeutic effects (Zhang et al., 2016). In the portal https://clinicaltrials.gov/, there are 133 clinical trials in different phases related directly or indirectly to sEVs, of which 55 directly use these nano elements in different evaluations, mostly related to cancer (Qiu et al., 2018).

In the exosome industry, currently, three main uses are defined:

a) as a diagnostic tool through liquid biopsy.

b) therapeutics of naturally produced sEVs.

c) Therapeutics of modified sEVs (approximately 34 companies work in this area, with a focus on cancer, neurodegenerative diseases, and exosome production and engineering).

In the diagnostics area, the case of the company Exosome Diagnostics Inc. (USA) stands out, which has 23 international patent applications published since 2015; It was recently acquired by Bio-Techne Corp. for $\$ 250$ million for its development for the diagnosis of lung and prostate cancer (Eom et al., 2015).

There are currently three prominent companies working on large-scale exosome production:

1. Evox Therapeutics, Ltd. (United Kingdom-Sweden) formed by the association between the University of Oxford and the Karolinska Institute, with 15 patent applications published since 2017; it is focused on the development of sEVs-based therapies for metabolic disorders (Yukawa and Baba, 2017).

2. Association between Rooster Bio Inc. \& Exopharm Pty. Ltd. (USA-Australia), the first dedicated to the commercialization of MSCS and associated products for their expansion at Research + Development and clinical level, and the second owner of the process to produce sEVs on a large scale and low cost with a focus on musculoskeletal diseases (Chen et al., 2017b).

3. Codiak BioSciences (USA) has created immortalized cell lines to homogenize the production of sEVs and modify their content, it has 5 international patent applications since 2017 (Harrell et al., 2019).
In the last 10 years, exosome-related companies have reached a global amount of USD 660 million, mainly comprising capital raising and public subsidies. In Chile, the companies Cells for Cells and Consorcio Regeneron develop two lines of work in sEVs:

a) Production of sEVs in a bioreactor system with culture medium without animal components and coupled to a tangential ultrafiltration system, to reduce the cost of production.

b) Antiangiogenic effect of sEVs-MSCS of menstrual fluid (MenSC) for the treatment of cancer; there have 2 patent applications to demonstrate the therapeutic effect at the preclinical level.

Since December 2019, SARS-CoV-2 infection has become an urgent public health event around the world. On February 13, 2020, more than 63,000 cases with more than 10,200 serious cases have been confirmed in mainland China. Although symptomatic and supportive care is recommended for severely infected people, those with advanced age and comorbidities such as diabetes and heart disease remain at high risk of adverse outcomes, with mortality of $\sim 10 \%$. Experimental studies have shown that MSCS and Exo-MSCS significantly reduced lung inflammation and pathological deterioration resulting from different types of lung injury (Yuan et al., 2019).

In addition, macrophage phagocytosis, bacterial death and results are improved. It is very likely that Exo-MSCS have the same therapeutic effect in inoculatory pneumonia as MSC itself ( $\mathrm{Li}$ et al., 2019). Although human bone marrow MSCS have been safely administered in patients with ARDS and septic shock (phase I/II trials), it appears safer to administer Exo-MSC rather than live MSCS. Intravenous administration of MSCS may result in aggregation or agglutination in the lesion, microcirculation and carries the risk of mutagenicity and oncogenicity, which do not exist when treating with nebulized Exo-MSCS. Another advantage of Exo-MSCS over MSC is the possibility of storing them for several weeks/months allowing their safe transport and delayed therapeutic use (Abraham and Krasnodembskaya, 2020, Gowen et al., 2020).

The purpose of this combined interventional clinical trial is to explore the safety and efficiency of inhalation of allogeneic adipose Exo-MSCS aerosols in the treatment of hospitalized patients with novel coronavirus pneumonia (Gowen et al., 2020).

\section{Conclusions}

The MSC represents a biomedicine area in permanent growth, not only in cell therapy but also in hematological diseases and cancer. MSCS presents differentiation mechanisms different from other kinds of stem cells, they are an interesting model for cell differentiation and plasticity. Even though the cells are currently having clinical use, there is much information on the biology of MSCS and their differentiation mechanism to generate a new classification that clarifies the morphological heterogeneity that has been described in several works that reflect different biological properties (Desrochers et al., 2016). Since 2003, in the European Union, cell therapy products with gene therapy products are considered drugs; both were introduced into the legislation 
through Directive 2003/63/EC41. In 2007, those therapies and tissue engineering were defined as advanced therapy drugs in Regulation (EC) No. 1394/2007. Those norms regulate the use of MSCS, defining them as somatic cell therapy, or medicinal therapy, which must contain viable cells, which can be subjected to expansion and in vitro culture during its manufacture (Jiang et al., 2002).

In clinical trials, it is important the sample origin selection as such as bone marrow, adipose tissue, umbilical cord, etcetera, the isolation method, if it is enzymatic or non-enzymatic, its selection by adherence or phenotype, the expansion process, and their procedures like culture media, xenogeneic-free, oxygen concentration, the maximum number of passes, etcetera. Future strategies for MSC in cell therapy must carry on those aspects to be able to be concretized and to unify the criteria of use and employability and homogeneity (Yen et al., 2005, Ding et al., 2015).

Nowadays, MSC manufacture must be subject to the Good Manufacturing Practice guide, where the quality and safety must be at least as guaranteed as any other product or another medication. Those standards include the quality control of the starting biological material, the reagents and fungible material used through the process of in vitro MSC expansion until reaching the required dose, and the excipients of the product final. Then, the manufacturing process must be aseptic, so the facilities must be qualified, processes, validated, and trained personnel to perform that work. The cellular drug finally obtained must meet previously defined specifications based on identity, purity, potency, dose, stability, and viability (In’tAnker et al., 2004, Hu et al., 2003).

The test results obtained in vitro and in vivo, define MSC as cell therapy, establish the necessary criteria for its manufacture as a therapeutic product, and ensure the quality during the process (Nawaz et al., 2016). This control is important to keep the reparative potential of MSC unchanged, immunomodulatory, and regenerative effects on the damaged tissue. For all this reason, MSC is presented in this work as a great therapeutic alternative to treat multiple disorders such as neurodegenerative, immune, or traumatic origin diseases. Even though there are still many obstacles that must be overcome when using MSCS in cell therapy, we enhance the study about its nature, applicability, and regulation through the microenvironment. Therefore, it is important to study the behavior of the different MSC populations about niches and not to generalize their therapeutic use. Unless there is an exact relation of the patients and illness to be treated.

Finally, it is important to comment on the growing industry interest in the production of extracellular vesicles. As of today, three companies (Capricor Inc., Anosys Inc., and ReNeuron Group, PLKC) are specializing in the development of therapies based on extracellular vesicles isolated from different sources (cells derived from cardiospheres, cell neural stem, and dendritic cell). Surprising that the therapeutic potential of these vesicles, the impact they currently have on the industry, and the development of clinical trials are still very limited.

One of the reasons that limit the incorporation of extracellular vesicles in clinical trials is the need for a standardization process in isolation of this. In this sense, although ultracentrifugation has traditionally been considered as the method that provides a higher degree of purity in the isolation of sEVs, this method, from the point industrially, is costly in terms of time and energy. Filtration-based methods could be an alternative for large-scale processing of cell culture supernatants, although for therapeutic applications this biological material must be produced under controlled conditions and following the regulation of good manufacturing practices. The establishment of good practices of manufacturing to obtain sEVs with a method of filtration requires quality controls that consider the size of the vesicles, presence/absence of biochemical markers, absence of contaminants (protein aggregates), sterility and stability of the final product, methods to optimize product storage and finally methods analytics that serve to control all aspects previously listed.

Even though the work presented here, when dealing with using experimental in vitro development, has evident limitations, the authors consider that MSC and their sEVs therapy is a controversial breakthrough in the treatment of incurable diseases. Many preclinical and clinical studies using sEVs-MSCs have been accomplished, but before therapeutic using them on a vast clinical scale, some issues should have been concerned, as the optimum dose and precise administration time should be concerned depend on the harshness of each disease. And finally understanding the fundamental mechanisms of action, manipulation, and preconditioning to produce safer and more effective MSCs and sEVs-MSCs for cell therapy.

Authors' Contribution: The authors confirm contribution to the paper as follows: study conception and design: O. RamirezFernandez, E. Zuñiga-Aguilar; data collection: O. RamirezFernandez, E. Zuñiga-Aguilar; draft manuscript preparation: O. Ramirez-Fernandez, E. Zuñiga-Aguilar. All authors reviewed the results and approved the final version of the manuscript.

Funding Statement: The authors received no specific funding for this review.

Conflicts of Interest: The authors declare that they have no conflicts of interest to report regarding the present review.

\section{References}

Abraham A, Krasnodembskaya A (2020). Mesenchymal stem cellderived extracellular vesicles for the treatment of acute respiratory distress syndrome. Stem Cells Translational Medicine 9: 28-38. DOI 10.1002/sctm.19-0205.

Alvarez ML, Khosroheidari M, KanchiRavi R, DiStefano JK (2012). Comparison of protein, microRNA, and mRNA yields using different methods of urinary exosome isolation for the discovery of kidney disease biomarkers. Kidney International 82: 1024-1032. DOI 10.1038/ki.2012.256.

Angelos MG, Kaufman DS (2015). Pluripotent stem cell applications for regenerative medicine. Current Opinion in Organ Transplantation 20: 663. DOI 10.1097/MOT.0000000000000244.

Asahara T, Murohara T, Sullivan A, Silver M, van der Zee R, Li T, Witzenbichler B, Schatteman G, Isner JM (1997). Isolation of putative progenitor endothelial cells for angiogenesis. Science 275: 964-967. DOI 10.1126/science.275.5302.964. 
Ashton BA, Allen TD, Howlett CR, Eaglesom CC, Hattori A et al. (1980). Formation of bone and cartilage by marrow stromal cells in diffusion chambers in vivo. Clinical Orthopaedics and Related Research 151: 294-307.

Bab I, Ashton BA, Gazit D, Marx G, Williamson MC et al. (1986). Kinetics and differentiation of marrow stromal cells in diffusion chambers in vivo. Journal Cell Science 84: 139-151. DOI 10.1242/jcs.84.1.139.

Bajada S, Mazakova I, Richardson JB, Ashammakhi N (2008). Updates on stem cells and their applications in regenerative medicine. Journal Tissue Engineering Regenerative Medicine 2: 169-183. DOI 10.1002/term.83.

Bieback K, Brinkmann I (2010). Mesenchymal stromal cells from human perinatal tissues: From biology to cell therapy. World Journal Stem Cells 2: 81-92. DOI 10.4252/wjsc.v2.i4.81.

Blazquez R, Sanchez-Margallo FM, de la Rosa O, Dalemans W, Alvarez V, Tarazona R et al. (2014). Immunomodulatory potential of human adipose mesenchymal stem cells derived SEVs on in vitro stimulated $\mathrm{T}$ cells. Frontiers Immunology 5: 556. DOI 10.3389/fimmu.2014.00556.

Börger V, Bremer M, Ferrer-Tur R, Gockeln L, Stambouli O, Becic A, Giebel B (2017). Mesenchymal stem/stromal cell-derived extracellular vesicles and their potential as novel immunomodulatory therapeutic agents. International Journal of Molecular Sciences 18: 1450. DOI 10.3390/ijms18071450.

Burrello J, Monticone S, Gai C, Gomez Y, Kholia S, Camussi G (2016). Stem cell-derived extracellular vesicles and immune-modulation. Frontiers in Cell and Developmental Biology 4: 83. DOI 10.3389/fcell.2016.00083.

Campagnoli C, Roberts IA, Kumar S, Bennett PR, Bellantuono I et al. (2001). Identification of mesenchymal stem/progenitor cells in human first-trimester fetal blood, liver, and bone marrow. Blood 98: 2396-2402. DOI 10.1182/blood.V98.8.2396.

Castro-Malaspina H, Gay RE, Resnick G, Kapoor N, Meyers P et al. (1980). Characterization of human bone marrow fibroblast colony-forming cells (CFU-F) and their progeny. Blood 56: 289-301. DOI 10.1182/blood.V56.2.289.289.

Chen B, Li Q, Zhao B, Wang Y (2017a). Stem cell-derived extracellular vesicles as a novel potential therapeutic tool for tissue repair. Stem Cells Translational Medicine 6: 17531758. DOI 10.1002/sctm.16-0477.

Chen CC, Liu L, Ma F, Wong CW, Guo XE et al. (2016). Elucidation of exosome migration across the blood-brain barrier model In vitro. Cellular and Molecular Bioengineering 9: 509-529. DOI 10.1007/s12195-016-0458-3.

Chen W, Yang M, Bai J, Li X, Kong X, Gao Y, Bi L, Xiao L, Shi B (2017b). Exosome-modified tissue engineered blood vessel for endothelial progenitor cell capture and targeted siRNA delivery. Macromolecular Bioscience 18. DOI 10.1002/mabi.201700242.

Cohen J (2013). Mesenchymal stem cell transplantation in multiple sclerosis. Journal of the Neurological Sciences 333: 43-49. DOI 10.1016/j.jns.2012.12.009.

Colter DC, Class R, DiGirolamo CM, Prockop DJ (2000). Rapid expansion of recycling stem cells in cultures of plasticadherent cells from human bone marrow. Proceedings of the National Academy of Science of the United States of America 97: 3213-3218. DOI 10.1073/pnas.97.7.3213.

Cvjetkovic A, Lötvall J, Lässer C (2014). The influence of rotor type and centrifugation time on the yield and purity of extracellular vesicles. Journal of Extracellular Vesicles 25. DOI 10.3402/jev.v3.23111.

Davis ME (2016). Exosomes: What do we love so much about them? Circulation Research 119: 1280-1282. DOI 10.1161/ CIRCRESAHA.116.309942.
Desrochers LM, Antonyak MA, Cerione RA (2016). Extracellular vesicles: Satellites of information transfer in cancer and stem cell biology. Developmental Cell 37: 301-309. DOI 10.1016/j.devcel.2016.04.019.

DiGirolamo C, Stokes D, Colter D, Phinney DG, Class R et al. (1999). Propagation and senescence of human marrow stromal cells in culture: A simple colony-forming assay identifies samples with the greatest potential to propagate and differentiate. British Journal of Hematology 107: 275-281. DOI 10.1046/ j.1365-2141.1999.01715.x.

Ding DC, Chang YH, Shyu WC, Lin SZ (2015). Human umbilical cord mesenchymal stem cells: A new era for stem cell therapy. Cell Transplantation 24: 339-347. DOI 10.3727/ 096368915 X686841.

Dominici M, Le Blanc K, Mueller I, Slaper-Cortenbach I, Marini F et al. (2006). Minimal criteria for defining multipotent mesenchymal stromal cells. The International Society for Cellular Therapy Position Statement. Cytotherapy 8: 315317. DOI 10.1080/1465324060008585905.

Duscher D, Barrera J, Wong VW, Maan ZN, Whittam AJ, Januszyk M, Gurtner GC (2016). Stem cells in wound healing: The future of regenerative medicine? A mini-review. Gerontologia 62: 216-225. DOI 10.1159/000381877.

Eom YW, Shim KY, Baik SK (2015). Mesenchymal stem cell therapy for liver fibrosis. The Korean Journal of Internal Medicine 30: 580. DOI 10.3904/kjim.2015.30.5.580.

Flores-Figueroa E, Arana-Trejo RM, Gutiérrez-Espíndola G, PérezCabrera A, Mayani H (2005). Mesenchymal stem cells in myelodysplastic syndromes: Phenotypic and cytogenetic characterization. Leukemia Research 29: 215-224. DOI 10.1016/j.leukres.2004.06.011.

Friedenstein AJ, Gorskaja JF, Kulagina NN (1976). Fibroblast precursors in normal and irradiated mouse hematopoietic organs. Experimental Hematology 4: 267-274. http:// europepmc.org/article/MED/976387.

Friedenstein AJ, Petrakova KV, Kurolesova AI, Frolova GP (1968). Heterotopic of bone marrow. Analysis of precursor cells for osteogenic and hematopoietic tissues. Transplantation 6: 230 247. https://journals.lww.com/transplantjournal/Abstract/1968/ 03000/HETEROTOPIC_TRANSPLANTS_OF_BONE_ MARROW.9.aspx.

Gálvez P, Clares B, Hmadcha A, Ruiz MA, Soria B (2013). Development of a cell-based medicinal product: Regulatory structures in the European Union. British Medical Bulettin 105: 85-105. DOI 10.1093/bmb/lds036.

Gálvez P, Ruiz A, Clares B (2011). El futuro de la medicina clínica hacia nuevas terapias: Terapia celular, génica y nanomedicina. Medicina Clínica (Barcelona) 137: 645-649. DOI 10.1016/j.medcli.2010.12.005.

Gastpar R, Gehrmann M, Bausero MA, Asea A, Gross C, Schroeder JA et al. (2005). Heat shock protein 70 surface-positive tumor sEVs stimulate migratory and cytolytic activity of natural killer cells. Cancer Responce 65: 5238-5247. DOI 10.1158/ 0008-5472.CAN-04-3804.

Giebel B, Kordelas L, Börger V (2017). Clinical potential of mesenchymal stem/stromal cell-derived extracellular vesicles. Stem Cell Investigation 4: 1-12. DOI 10.21037/sci.2017.09.06.

Gimble J, Guilak F, Nuttall M, Sathishkumar S, Vidal M et al. (2008). In vitro differentiation potential of mesenchymal stem cells. Transfusion Medicine and Hemotheray 35: 228-238. DOI 10.1159/000124281.

Golchin A, Seyedjafari E, Ardeshirylajimi A (2020). Mesenchymal stem cell therapy for COVID-19: Present or future. Stem 
Cell Reviews and Reports 16: 427-433. https://link.springer. com/article/10.1007/s12015-020-09973-w.

Gonda K, Shigeura T, Sato T, Matsumoto D, Suga H et al. (2008). Preserved proliferative capacity and multipotency of human adipose-derived stem cells after long-term cryopreservation. Plastic and Reconstructive Surgery 121: 401-410. DOI 10.1097/01.prs.0000298322.bc.

Gowen A, Shahjin F, Chand S, Odegaard KE, Yelamanchili SV (2020). Mesenchymal stem cell-derived extracellular vesicles: Challenges in clinical applications. Frontiers in Cell and Developmental Biology 8: 1-8. DOI 10.3389/fcell.2020.00149.

Han Y, Li X, Zhang Y, Han Y, Chang F, Ding J (2019). Mesenchymal stem cells for regenerative medicine. Cells 8: 886. DOI 10.3390/cells8080886.

Harrell CR, Jovicic N, Djonov V, Arsenijevic N, Volarevic V (2019). Mesenchymal stem cell-derived exosomes and other extracellular vesicles as new remedies in the therapy of inflammatory diseases. Cells 8: 1605. DOI 10.3390/cells8121605.

Haynesworth SE, Baber MA, Caplan AI (1992). Cell surface antigens on human marrow-derived mesenchymal cells are detected by monoclonal antibodies. Bone 13: 69-80. DOI 10.1016/ 8756-3282(92)90363-2.

Heil M, Ziegelhoeffer T, Mees B, Schaper W (2004). A different outlook on the role of bone marrow stem cells in vascular growth: Bone marrow delivers software not hardware. Circulation Research 94: 573-574. DOI 10.1161/01. RES.0000124603.46777.EB.

Herzog E, Chai L, Krause D (2003). Plasticity of marrow-derived stem cells. Blood 102: 3483-3493. DOI 10.1182/bllod-200305-1664.

Hooper C, Sainz-Fuertes R, Lynham S, Hye A, Killick R, Warley A et al. (2012). Wnt3a induces exosome secretion from primary cultured rat microglia. BMC Neuroscience 13: 144 . DOI 10.1186/1471-2202-13-144.

Horwitz E, Prockop D, Fitzpatrick L, Koo WWK, Gordon PL et al. (1999). Transplantability and therapeutic effects of bone marrow-derived mesenchymal cells in children with osteogenesis imperfecta. Nature Medicine 5: 309-313. DOI $10.1038 / 6529$.

Horwitz EM, Le Blanc K, Dominici M, Mueller I, SlaperCortenbach I et al. (2005). Clarification of the nomenclature for MSC: The International Society for Cellular Therapy position statement. Cytotherapy 7: 393395. DOI 10.1080/146532405000319234.

Hu Y, Liao L, Wang Q, Ma L, Ma G et al. (2003). Isolation and identification of mesenchymal stem cells from human fetal pancreas. Journal of Laboratory and Clinical Medicine 141: 342-349. DOI 10.1016/S0022-2143(03)00022-2.

Hur YH, Cerione RA, Antonyak MA (2020). Extracellular vesicles and their roles in stem cell biology. Stem Cells 38: 469-476. DOI 10.1002/stem.3140.

Ibrahim AGE, Cheng K, Marbán E (2014). SEVs as critical agents of cardiac regeneration triggered by cell therapy. Stem Cell Reports 2: 606-619. DOI 10.1016/j.stemcr.2014.04.006.

In'tAnker PS, Scherjon SA, Kleijburg-van der Keur C, Noort WA, Claas FHJ et al. (2003). Amniotic fluid as a novel source of mesenchymal stem cells for therapeutic transplantation. Blood 102: 1548-1549. DOI 10.1182/blood-2003-04-1291.

In'tAnker PS, Scherjon SA, Kleijburg-van der Keur C, Groot-Swings MJS, Claas FHJ et al. (2004). Isolation of mesenchymal stem cells of fetal or maternal origin from human placenta. Stem Cells 22: 1338-1345. DOI 10.1634/stemcells.2004-0058.
Jeter C, Badeaux M, Choy G (2009). Functional evidence that the selfrenewal gene NANOG regulates human tumos development. Stem Cells 27: 993-1005. DOI 10.1002/stem.29.

Jiang Y, Jahagirdar B, Rheinhardt R, Schwartz R, Keene C et al. (2002). Pluripotency of mesenchymal stem cells from adult marrow. Nature 418: 41-49. DOI 10.1038/nature00870.

Kern S, Eichler H, Stoeve J, Klüter H, Bieback K (2006). Comparative analysis of mesenchymal stem cells from bone marrow, umbilical cord blood, or adipose tissue. Stem Cells 24: 1294-1301. DOI 10.1634/stemcells.2005-0342.

Keshtkar S, Azarpira N, Ghahremani MH (2018). Mesenchymal stem cell-derived extracellular vesicles: Novel frontiers in regenerative medicine. Stem Cell Research \& Therapy 9: 1-9. DOI 10.1186/s13287-018-0791-7.

Kim N, Cho S (2013). Clinical applications of mesenchymal stem cells. Korean Journal of Internal Medicine 28: 387-402. DOI 10.3904/kjim.2013.28.4.387.

Kinnaird T, Stabile E, Brunett MS, Lee CW, Barr S et al. (2004). Marrow-derived stromal cells express genes encoding a broad spectrum of arteriogenic cytokines and promote in vitro and in vivo arteriogenesis through paracrine mechanisms. Circulation Research 94: 678-685. DOI 10.1161/01. RES.0000118601.37875.AC.

Koch C, Reck K, Shao K, Lin Q, Joussen S et al. (2013). Pluripotent stem cells escape from senescence-associated DNA methylation changes. Genome Research 23: 248-259. DOI 10.1101/gr.141945.112.

Kong D, Banerjee S, Ahmad A, Li Y, Wang Z, Sethi S, Sarkar FH (2010). Epithelial to mesenchymal transition is mechanistically linked with stem cell signatures in prostate cancer cells. PLoS One 5: e12445. DOI 10.1371/journal.pone.0012445.

Kumar P, Kandoi S, Misra R, Vijayalakshmi S, Rajagopal K, Verma RS (2019). The mesenchymal stem cell secretome: A new paradigm towards cell-free therapeutic mode in regenerative medicine. Cytokine \& Growth Factor Reviews 46: 1-9. DOI 10.1016/j.cytogfr.2019.04.002.

Kurtzberg J, Prockop S, Teira P, Bittencourt H, Lewis V et al. (2014). Allogeneic human mesenchymal stem cell therapy (remestemcel-L, Prochymal) as a rescue agent for severe refractory acute graft-versus-host disease in pediatric patients. Biology Blood Marrow Transplant 20: 229-235. DOI 10.1016/j.bbmt.2013.11.001.

Kadiyala S, Jaiswal N, Bruder SP (1997). Culture-expanded bone marrow-derived mesenchymal stem cells can regenerate a critical-sized segmental bone defect. Tissue Engineering 3: 173-185.

Lai RC, Yeo RWY, Lim SK (2015). Mesenchymal stem cell exosomes. Seminars in Cell \& Developmental Biology 40: 82-88. DOI 10.1016/j.semcdb.2015.03.001.

Lakshmipathy U, Verfaille C (2005). Stem cell plasticity. Blood Reviews 19: 29-38. DOI 10.1016/j.blre.2004.03.001.

Lane RE, Korbie D, Anderson W, Vaidyanathan R, Trau M (2005). Analysis of exosome purification methods using a model liposome system and tunable-resistive pulse sensing. Scientific Reports 5: 7639. DOI 10.1038/srep07639.

Lazarus H, Haynesworth S, Gerson S, Rosenthal N, Caplan A (1995). Ex vivo expansion and subsequent infusion of human bone marrow-derived stromal progenitor cells: Implications for therapeutic use. Bone Marrow Transplantation 16: $557-564$.

Li R, Li M, Chen J (2016). Clinical efficacy and safety of autologous stem cell transplantation for patients with ST-segment elevation 
myocardial infarction. Therapeutics and Clinical Risk Management 12: 1171-1189. DOI 10.2147/TCRM.S107199.

Li C, Jiao G, Wu W, Wang H, Ren S, Zhang L, Chen Y (2019a). Exosomes from bone marrow mesenchymal stem cells inhibit neuronal apoptosis and promote motor function recovery via the Wnt/ $\beta$-catenin signaling pathway. Cell Transplantation 28: 1373-1383. DOI 10.1177/0963689719870999.

Li Z, Liu F, He X, Yang X, Shan F, Feng J (2019b). Exosomes derived from mesenchymal stem cells attenuate inflammation and demyelination of the central nervous system in EAE rats by regulating the polarization of microglia. International Immunopharmacology 67: 268-280. DOI 10.1016/j.intimp.2018.12.001.

Lukomska B, Stanaszek L, Zuba-Surma E, Legosz P, Sarzynska S, Drela K (2019). Challenges and controversies in human mesenchymal stem cell therapy. Stem Cells International 16: 427-433. DOI 10.1155/2019/9628536.

Marappagounder D, Somasundaram I, Dorairaj S, Sankaran R (2013). Differentiation of mesenchymal stem cells derived from human bone marrow and subcutaneous adipose tissue into pancreatic islet-like clusters in vitro. Cellular and Molecular Biology Letters 18: 75-88. DOI 10.2478/s11658012-0040-5.

Mauney JR, Volloch V, Kaplan DL (2005). Role of adult mesenchymal stem cells in bone tissue engineering applications: Current status and future prospects. Tissue Engineering 11: 787-802. DOI 10.1089/ten.2005.11.787.

Menard C, Pacelli L, Bassi G, Dulong J, Bifari F et al. (2013). Clinicalgrade mesenchymal stromal cells produced under various good manufacturing practice processes differ in their immunomodulatory properties: Standardization of immune quality controls. Stem Cells and Development 22: 17891801. DOI 10.1089/scd.2012.0594.

Mets T, Verdonk G (1981). Variations in the stromal cell population of human bone marrow during aging. Mechanisms of Ageing and Development 15: 41-49. DOI 10.1016/0047-6374(81)90006-3.

Nakahara H, Dennis JE, Bruder SP, Haynesworth SE, Lennon DP et al. (1991). In vitro differentiation of bone and hypertrophic cartilage from periosteal-derived cells. Experimental Cell Research 195: 492-503. DOI 10.1016/ 0014-4827(91)90401-F.

Nauta AJ, Fibbe WE (2007). Immunomodulatory properties of mesenchymal stromal cells. Blood 110: 3499-3506. DOI 10.1182/blood-2007-02-069716.

Nawaz M, Fatima F, Vallabhaneni KC, Penfornis P, Valadi H, Ekström K, Camussi G (2016). Extracellular vesicles: Evolving factors in stem cell biology. Stem Cells International 9: 1-9. DOI 10.1155/2016/1073140.

Oswald J, Boxberger S, Jørgensen B, Feldmann S, Ehninger G et al. (2004). Mesenchymal stem cells can be differentiated into endothelial cells in vitro. Stem Cells 22: 377-384. DOI 10.1634/stemcells.22-3-377.

Paik DT, Chandy M, Wu JC (2020). Patient and disease-specific induced pluripotent stem cells for discovery of personalized cardiovascular drugs and therapeutics. Pharmacological Reviews 72: 320-342. DOI 10.1124/pr.116.013003.

Park Y, Ha C, Lee C, Yoon Y, Park Y (2016). Cartilage regeneration in osteoarthritic patients by a composite of allogeneic umbilical cord blood-derived mesenchymal stem cells and hyaluronate hydrogel: Results from a clinical trial for safety and proof-of-concept with 7 years of extended follow-up. Stem Cells Translational Medicine 6: 613-621. DOI 10.5966/sctm.2016-0157.
Park KS, Bandeira E, Shelke GV, Lässer C, Lötvall J (2019). Enhancement of therapeutic potential of mesenchymal stem cell-derived extracellular vesicles. Stem Cell Research \& Therapy 10: 1-15. DOI 10.1186/s13287-019-1398-3.

Peired A, Sisti A, Romagnani P (2016). Mesenchymal stem cell-based therapy for kidney disease: A review of clinical evidence. Stem Cells International ID 2016: 1-22. DOI 10.1155/2016/4798639.

Pereira R, Halford K, O'Hara M, Leeper DB, Sokolov BP et al. (1995). Cultured adherent cells from marrow can serve as longlasting precursor cells for bone, cartilage, and lung in irradiated mice. Proceedings of the National Academy of Science of the United States of America 92: 4857-4861. DOI 10.1073/pnas.92.11.4857.

Pereira RF, O'Hara MD, Laptev AV, Halford KW, Pollard MD et al. (1998). Marrow stromal cells as a source of progenitor cells of nonhematopoietic tissues in transgenic mice with a phenotype of osteogenesis imperfecta. Proceedings of the National Academy of Science of the United States of America 95: 1142-1147. DOI 10.1073/pnas.95.3.1142.

Piersma A, Ploemacher R, Brockbank K (1983). Transplantation of bone marrow fibroblastoid stromal cells in mice via the intravenous route. British Journal of Hematology 54: 285290. DOI 10.1111/j.1365-2141.1983.tb02097.x.

Pittenger MF, Mackay AM, Beck SC, Jaiswal RK, Douglas R et al. (1999). Multilineage potential of adult human mesenchymal stem cells. Science 248: 143-147. DOI 10.1126/science.284.5411.143.

Prockop DJ, Sekiya I, Colter DC (2001). Isolation and characterization of rapidly self-renewing stem cells from cultures of human marrow stromal cells. Cytotherapy 3: 393-396. DOI 10.1080/ 146532401753277229.

Qian X, An N, Ren Y, Yang C, Zhang X et al. (2020). Immunosuppressive Effects of Mesenchymal Stem Cells-derived Exosomes. Stem Cell Reviews and Reports 17: 411-427. DOI 10.1007/s12015-02010040-7.

Qiu G, Zheng G, Ge M, Wang J, Huang R, Shu Q, Xu J (2018). Mesenchymal stem cell-derived extracellular vesicles affect disease outcomes via transfer of microRNAs. Stem Cell Research \& Therapy 9: 1-9. DOI 10.1186/s13287-018-1069-9.

Reissis D, Tang Q, Cooper N, Carasco CF, Gamie Z et al. (2016). Current clinical evidence for the use of mesenchymal stem cells in articular cartilage repair. Expert Opinion on Biology Therapy 16: 535-557. DOI 10.1517/14712598.2016.1145651.

Reyes M, Lund T, Lenvik T, Aguiar D, Koodie L et al. (2001). Purification and ex vivo expansion of postnatal human marrow mesodermal progenitor cells. Blood 98: 2615-2625. DOI 10.1182/blood.V98.9.2615.

Ryan J, Barry F, Murphy J, Mahon B (2005). Mesenchymal stem cells avoid allogeneic rejection. Journal of Inflammation 2: 8. DOI 10.1186/1476-9255-2-8.

Ryan J, Barry F, Murphy J, Mahon B (2007). Interferon-gamma does not break, but promotes the immunosuppressive capacity of adult human mesenchymal stem cells. Clinical and Experimental Immunology 149: 353-363. DOI 10.1111/ j.1365-2249.2007.03422.x.

Safford K, Hicok K, Safford S, Halvorsen Y, Wilkison W et al. (2002). Neurogenic differentiation of murine and human adiposederived stromal cells. Biochemical and Biophysical Reserach Communications 294: 371-379. DOI 10.1016/S0006-291X (02)00469-2.

Sandhu J, Clark B, Boynton E, Atkins H, Messner H et al. (1996). Human hematopoiesis in SCID mice implanted with human adult cancellous bone. Blood 88: 1973-1982. DOI 10.1182/blood.V88.6.1973.bloodjournal8861973. 
Sarker S, Scholz-Romero K, Perez A, Illanes SE, Mitchell MD, Rice GE et al. (2014). Placenta-derived sEVs continuously increase in maternal circulation over the first trimester of pregnancy. Journal of Translational Medicine 12: 204. DOI 10.1186/1479-5876-12-204.

Schipanski D, Knoepffler N, Sorgner SL (2016). Humanbiotechnology as social challenge: An interdisciplinary introduction to bioethics. Routledge.

Sung S, Hwan B, Weaver AM (2017). Exosome secretion promotes chemotaxis of cancer cells. Cell Adhesion \& Migration 2. DOI 10.1080/19336918.2016.1273307.

Tofiño-Vian M, Guillén MI, Del Caz MDP, Silvestre A, Alcaraz MJ (2018). Microvesicles from human adipose tissue-derived mesenchymal stem cells as a new protective strategy in osteoarthritic chondrocytes. Cellular Physiology and Biochemistry 47: 11-25. DOI 10.1159/000489739.

Trounson A, McDonald C (2015). Stem cell therapies in clinical trials: Progress and challenges. Cell Stem Cell 17: 11-22. DOI 10.1016/j.stem.2015.06.007.

Tse W, Pendleton D, Beyer W, D’Andréa A, Guinan E (2000). Bone marrow-derived mesenchymal stem cells suppress $\mathrm{T}$ cell activation without inducing anergy. Blood 96: 112-134. https://www.scholars.northwestern.edu/en/ publications/bone-marrow-derived-mesenchymal-stem-cellssuppress-t-cell-activa.

Urbanelli L, Buratta S, Sagini K, Ferrara G, Lanni M, Emiliani C (2015). Exosome-based strategies for diagnosis and therapy. Recent Patents on CNS Drug Discovery (Discontinued) 10: 10-27. https://www.ingentaconnect.com/content/ben/prn/ 2015/00000010/00000001/art00006.

Wakitani S, Saito T, Caplan A (1995). Myogenic cells derived from rat bone marrow mesenchymal stem cells exposed to 5azacytidine. Muscle and Nerve 18: 1417-1426. DOI 1002/ mus. 880181212.

Wang HS, Hung SC, Peng ST, Huang CC, Wei HM et al. (2004). Mesenchymal stem cells in the Wharton's jelly of the human umbilical cord. Stem Cells 22: 1330-1337. DOI 10.1634/stemcells.2004-0013.

Yen BL, Huang HI, Chien CC et al. (2005). Isolation of multipotent cells from human term placenta. Stem Cells 23: 3-9. DOI 10.1634/stemcells.2004-0098.

Yuan O, Lin C, Wagner J, Anderson JS, Archard JA, Deng P, Anderson JD (2019). Exosomes derived from human primed mesenchymal stem cells induce mitosis and potentiate growth factor secretion. Stem Cells and Development 28: 398-409. DOI 10.1089/scd.2018.0200.

Yukawa H, Baba Y (2017). In vivo fluorescence imaging and the diagnosis of stem cells using quantum dots for regenerative medicine. Analytical Chemistry 89: 2671-2681. DOI 10.1021/acs.analchem.6b04763.

Zhang B, Yeo RWY, Tan KH, Lim SK (2016). Focus on extracellular vesicles: Therapeutic potential of stem cell-derived extracellular vesicles. International Journal of Molecular Sciences 17: 174. DOI 10.3390/ijms17020174.

Zhao K, Lou R, Huang F, Peng Y, Jiang Z et al. (2015). Immunomodulation effects of mesenchymal stromal cells on acute graft-versus-host diseases after hematopoietic stem cell transplantation. Biology of Blood and Marrow Transplantation 21: 97-104. DOI 10.1016/j.bbmt.2014.09.030.

Zhao L, Duan W, Reyes M, Dirk Keene C, Verfaillie CM et al. (2002). Human bone marrow stem cells exhibit neural phenotypes and ameliorate neurological deficits after grafting into the ischemic brain of rats. Experimental Neurology 174: 11-20. DOI 10.1006/exnr.2001.7853.

Zomer HD, Vidane AS, Gonçalves NN, Ambrósio CE (2015). Mesenchymal and induced pluripotent stem cells: General insights and clinical perspectives. Stem Cells Cloning 8: 125-134. DOI 10.2147/SCCAA.S88036.

Zuk P, Zhu M, Ashjian P,Ugarte D, Huang J et al. (2002). Human adipose tissue is a source of multipotent stem cells. Molecular Biology of the Cell 13: 4279-4295. DOI 10.1091/ mbc.e02-02-0105. 